\title{
Adipose-Derived Stem Cells Inhibited the Proliferation of Bladder Tumor Cells by S Phase Arrest and $\mathrm{Wnt} / \beta$-Catenin Pathway
}

\author{
Tao Wang, ${ }^{1, *}$ Xi Yu, ${ }^{1, *}$ Jian Lin, ${ }^{2}$ Cong Qin, ${ }^{1}$ Tao Bai, ${ }^{1}$ Tao Xu, ${ }^{1}$ Lei Wang, ${ }^{1}$ Xiuheng Liu, ${ }^{1, *}$ and Shenglan Li ${ }^{3,{ }^{* *}}$
}

\begin{abstract}
Adipose-derived stem cells (ADSCs), which are present in most organs and tissues, were evaluated as a novel medium for stem cell therapy. In this study, we investigated the effects and underlying mechanisms of ADSCs in bladder tumor (BT) cells. SV-HUC, T24, and EJ cells were cultured with ADSCs and conditioned medium from ADSCs (ADSC-CM). We observed that in routine culture, ADSCs significantly inhibited the proliferation of T24 and EJ cells in a dose-dependent manner. In addition, ADSC-CM attenuated the viability of T24 and EJ cells in a dose-dependent manner. Cell cycle analysis indicated that ADSC-CM was capable of inducing T24 and EJ cells S phase arrest and downregulating the expression of CDK 1, whereas the expression of cyclin A was increased. ADSC-CM could induce apoptosis in T24 cells. The mechanism of this effect likely involved the caspase $3 / 7$ pathway and $\mathrm{Wnt} / \beta$-catenin pathway. These findings demonstrated that ADSCs could inhibit the proliferation of BT cells via secretory factors.
\end{abstract}

Keywords: adipose-derived stem cell, bladder tumor, $\mathrm{S}$ phase arrest, caspase $3 / 7, \mathrm{Wnt} / \beta$-catenin

\section{Introduction}

$\mathbf{I}^{\mathrm{s}}$ N 2018, BLADDER TUMOR (BT) was the second most common malignancy of the genitourinary tract with almost 80,000 newly diagnosed cases and almost 17,000 deaths in the USA (Siegel et al., 2019). The treatment schemes for BT such as surgical techniques, including minimally invasive surgery are various, and there has been an improvement in the understanding of multimodal treatments involving radiotherapy, chemotherapy, and immunotherapy (DeGeorge et al., 2017). These treatments are considered costly and bring a huge economic burden to patients. The high recurrence rate and unsatisfactory 5-year overall survival rate for BT are still in need of improvement (Jin et al., 2014). Thus, novel treatments for BT need to be identified.

Adipose-derived stem cells (ADSCs) isolated from the stromal vascular fraction of adipose tissue share the same characteristics as mesenchymal stem cells (MSCs) and can differentiate into adipogenic, myogenic, osteogenic, chondrogenic, and neurogenic cells (Nielsen et al., 2018; Zachar et al., 2011). Currently, many studies have linked many important growth factors, cytokines, and chemokines secreted by ADSCs and MSCs to cancer development and progression (Chen et al., 2018; Chu et al., 2018; Gazdic et al., 2017; Lu et al., 2016). However, there is debate over the ability of ADSCs to support or suppress tumor cell proliferation (Chu et al., 2015; Jing et al., 2016; Yu et al., 2015).

The present study was designed to reveal the effects of ADSCs on the growth of BT cells and to explore the underlying mechanisms of these effects. In this study, we provide evidence that secretome of ADSCs were able to influence T24 cells and EJ cells proliferation/apoptosis by $S$ phase arrest and $\mathrm{Wnt} / \beta$-catenin pathway. Maybe ADSCs secretome can be used as a treatment for BT patients in the future.

\footnotetext{
${ }^{1}$ Department of Urology, Renmin Hospital of Wuhan University, Wuhan, China.

${ }^{2}$ Department of Urology, Peking University First Hospital, Beijing, China.

${ }^{3}$ Department of Radiography, Renmin Hospital of Wuhan University, Wuhan, China.

*Co-first authors.

**Corresponding authors.
}

(c) Tao Wang, et al., 2019. Published by Mary Ann Liebert, Inc. This Open Access article is distributed under the terms of the Creative Commons License (http://creativecommons.org/licenses/by/4.0), which permits unrestricted use, distribution, and reproduction in any medium, provided the original work is properly credited. 


\section{Materials and Methods}

Chemicals and reagents

Collagenase I was purchased from Sigma-Aldrich (St. Quentin Fallavier, France). Fetal bovine serum (FBS) for ADSCs was purchased from Gibco (Paris, France). Trypsin, Dulbecco's modified Eagle's medium with high glucose (DMEM), penicillin, streptomycin, and phosphate-buffered saline (PBS) were provided by HyClone (Cergy-Pontoise, France).

\section{ADSC preparation and culture}

Adipose tissue was obtained from the subcutaneous fat of 10 patients who underwent renal resection without tumor at the Department of Urology in Renmin Hospital of Wuhan University. All donors provided written informed consent. This study was conducted according to institutional guidelines and an approved protocol. ADSCs were isolated and cultured as we previously described (Yu et al., 2015). The researcher washed adipose tissue samples with sterile PBS to remove debris and red blood cells and then cut them into tiny pieces.

The tissues were digested by $0.1 \%$ collagenase $\mathrm{I}$ in DMEM at $37^{\circ} \mathrm{C}$ for 60 minutes with gentle agitation. Then, the mixture was centrifuged for 10 minutes at $1000 \mathrm{r} / \mathrm{min}$. The cellular precipitate was then resuspended and filtered through a 100-m mesh filter. The filtrate was plated onto cell culture plates in the indicated culture medium (DMEM with $10 \% \mathrm{FBS}$ ) and maintained in an incubator at $37^{\circ} \mathrm{C}$ in $5 \%$ $\mathrm{CO}_{2}$ in the indicated culture medium (DMEM with $10 \%$ FBS). Cells at passages 3-6 were used for subsequent experiments.

\section{Cancer cell culture}

SV-HUC, T24, and EJ cells were purchased from the Institute of Urology, Peking University. SV-HUC cells were cultured in F-12K containing 10\% FBS. T24 and EJ cells were cultured in DMEM containing 10\% FBS. Cells were grown in an incubator at $37^{\circ} \mathrm{C}$ in $5 \% \mathrm{CO}_{2}$.

\section{Conditioned medium collection}

About $5 \times 10^{4}$ cells were cultured in complete medium in 6 -well plates for 24 hours. The conditioned medium was collected from cultured cells after incubation in a serum-free medium for 24 hours. The medium was then filtered and used immediately, or stored at $-80^{\circ} \mathrm{C}$.

\section{Cell number assessment}

Cells were cultured in 6-well plates for 24 hours, before serum starvation for 16 hours. Test groups were cocultured with ADSCs in a $1.0 \mu \mathrm{m}$ transwell membrane for another 48 hours. Control groups were cultured with tumor cells. Cell number was counted by using a cell counter model (Muse).

\section{Cell viability assay}

Cells were cultured in 96-well plates for 24 hours, before serum starvation for 16 hours. Test groups were cultured in ADSC-CM for another 48 hours in triplicate. Control groups were cultured in normal medium. Cell viability was then measured by MTS assay (CellTiter96 AQueous Assay; Promega, France).

\section{Cell cycle distribution analysis}

Cells were cultured at concentrations to yield $40 \%-50 \%$ before treated with ADSC-CM or normal medium. After 48 hours, cells were harvested and washed twice with PBS, then centrifuged. The samples were fixed with $70 \%$ ethanol for at least 12 hours at $4^{\circ} \mathrm{C}$. The cells were washed with PBS once to remove the ethanol and resuspended with propidium iodide solution $(0.05 \mathrm{mg} / \mathrm{mL})$ containing Triton-100 and RNase, incubated at $37^{\circ} \mathrm{C}$ for 30 minutes in the dark. DNA content was then analyzed using the FC500 flow cytometer.

\section{Western blot analysis}

Cells were cultured for 48 hours with ADSC-CM or normal medium. Total protein extracts were obtained by lysing cells in cold radioimmunoprecipitation assay (RIPA) buffer with $1 \%$ phenylmethanesulfonyl fluoride (PMSF). Equal amounts of cell extract were resolved by SDS-PAGE and transferred onto nitrocellulose filter membrane (Millipore, Bedford, MA) and blocked with 5\% nonfat milk in Tris-buffered saline (TBS)/Tween $(0.05 \%$ Tween-20 in TBS). Blots were probed with glyceraldehyde-3-phosphate dehydrogenase (GAPDH), Cyclin A, CDK1, and $\beta$-catenin antibodies (CST, Beverly, MA). At last, they were developed using a Chemiluminescence Kit (Millipore) with G:BOX Chemi XL1. GENESys (Syngene, Cambridge, UK).

\section{Apoptosis assay}

Cells were harvested after been treated with the ADSC-CM or T24-CM for 48 hours, washed with PBS twice, resuspended in $1 \times$ binding buffer at a concentration of about $1 \times 10^{6}$ cells $/ \mathrm{mL}$. We used a FITC Annexin V Apoptosis Detection Kit I (BD Biosciences). Five micro liter annexin $\mathrm{V}-\mathrm{FITC}$ and $5 \mu \mathrm{L} 7-\mathrm{AAD}$ was added into $100 \mu \mathrm{L}$ solution and left it in the dark for 15 minutes. Then $400 \mu \mathrm{L} 1 \times$ binding buffer was added into the mixture. Cells were analyzed by flow cytometry using CELL Quest Pro software.

\section{Assessment of activated caspase-3/7}

A caspase-3/7 activation assay was performed using a Caspase-Glo $^{\mathrm{TM}}$ 3/7 Assay Kit (Promega, France) in accordance with the protocol. T24 cells were cultured in 24-well plates for 24 hours, before serum starvation for 16 hours. Test groups were cultured in ADSC-CM for another 48 hours, while control groups were cultured in T24-CM. Caspase-Glo $3 / 7$ reagent $(100 \mu \mathrm{L})$ was then added to each well, and the plate was incubated at room temperature for 1 hour. The luminescence of each sample was measured with a GloMax-Multi Detection System (Promega).

\section{Statistical analysis}

All data were analyzed by SPSS software (version 20.0). The results are expressed as the mean \pm standard deviation. Statistical analyses were performed using Student's $t$-test. $p<0.05$ was considered significant. All means were calculated from at least three independent experiments. 
A
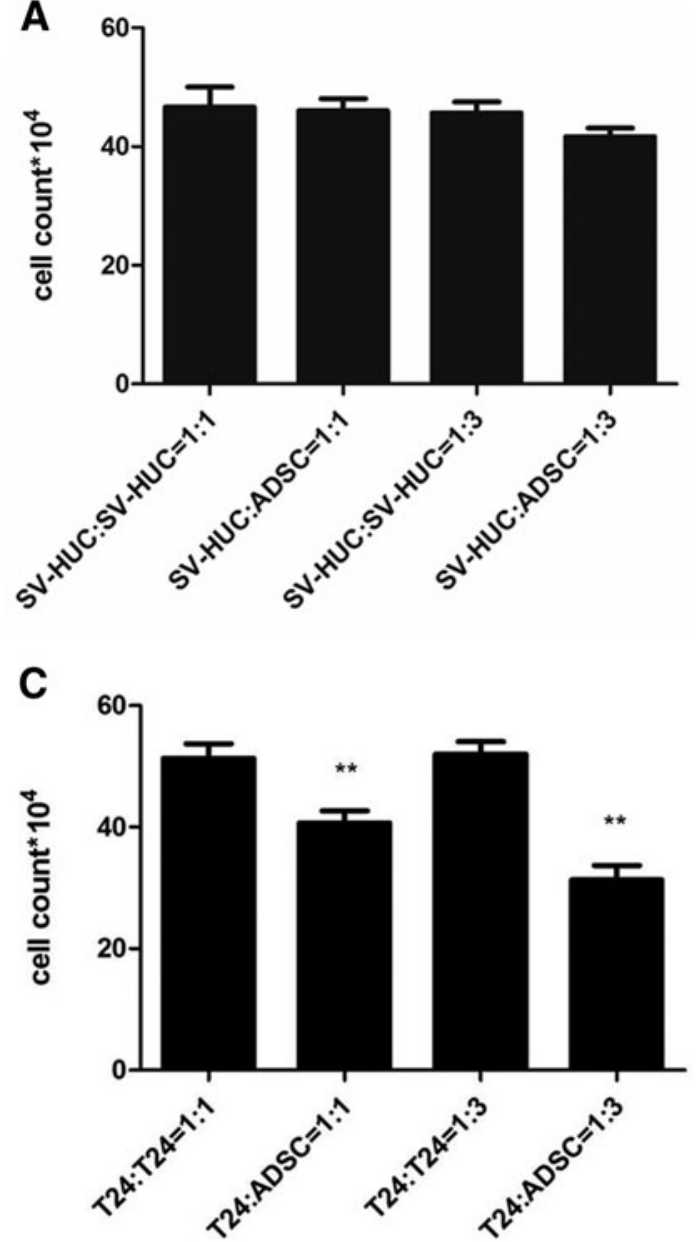

$\mathbf{E}$

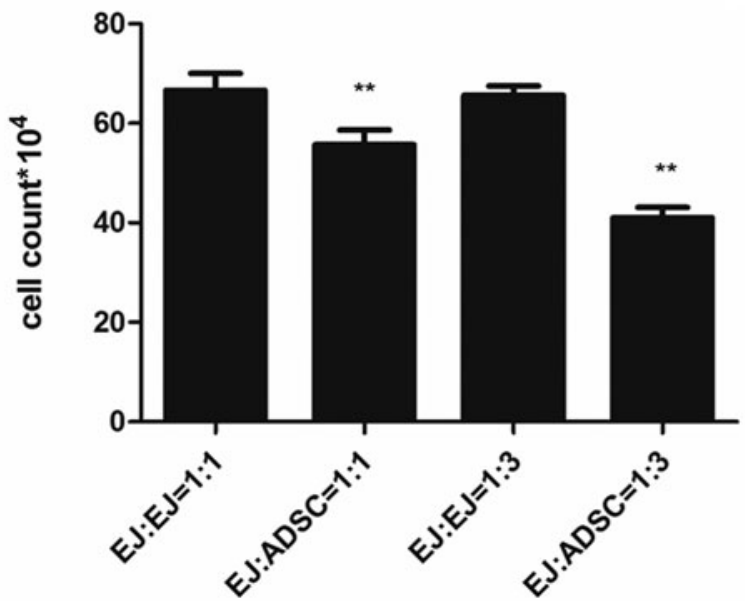

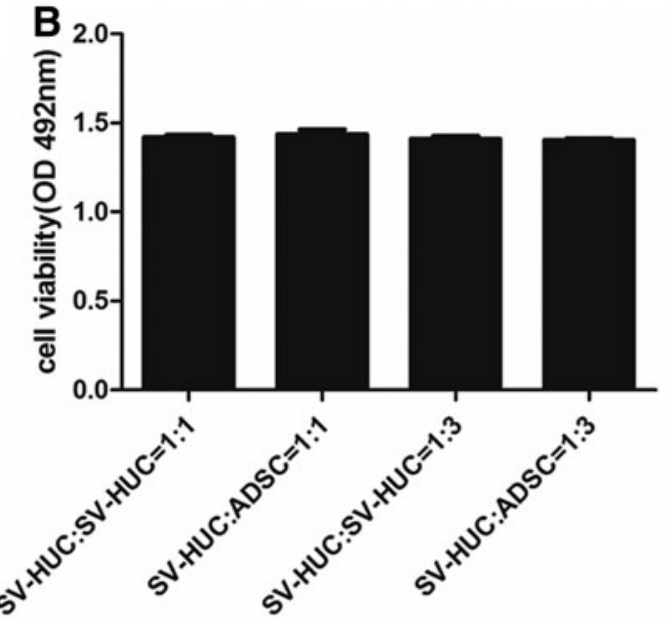

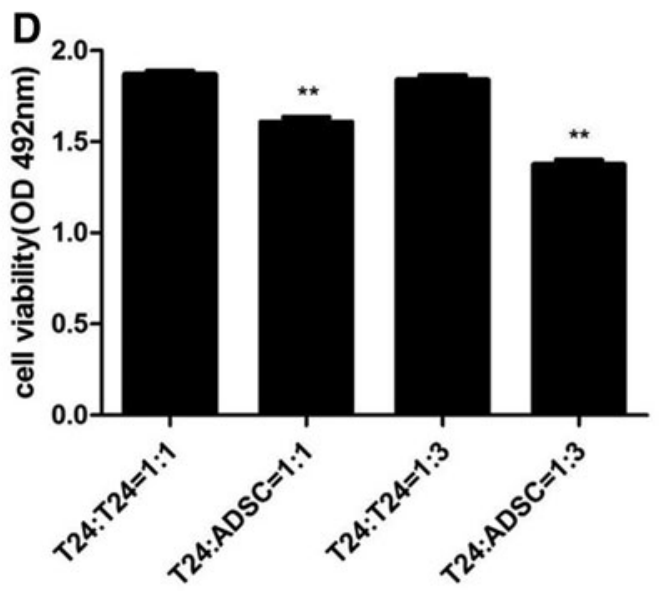

$\mathbf{F}$

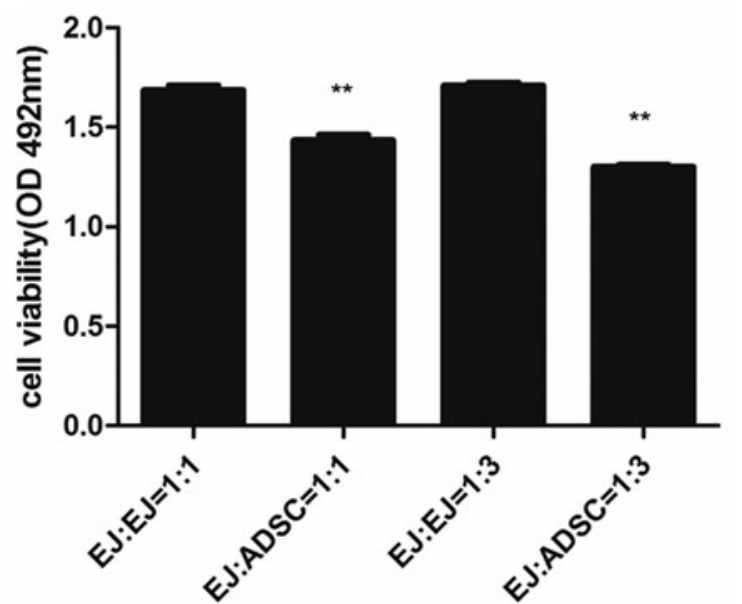

FIG. 1. Effect of ADSCs on the growth and viability of SV-HUC, T24, and EJ cells. SV-HUC, T24, and EJ cells were, respectively, cocultured with SV-HUC, T24, and EJ or ADSCs at ratios of 1:1 and 3:1. The growth (A) or viability (B) of SV-HUC treated by ADSCs or ADSC-CM showed no significance versus control. The number of T24 (C) and EJ (E) cells was less in the treated group than the control group in dose-dependent manner. T24 (D) and EJ (F) cells viability was also inhibited by ADSC-CM in dose-dependent manner. Data shown are the mean \pm SD of three independent experiments $(* * p<0.01$ vs. control). ADSCs, adipose-derived stem cells; SD, standard deviation. 
CDK1

Cyclin A

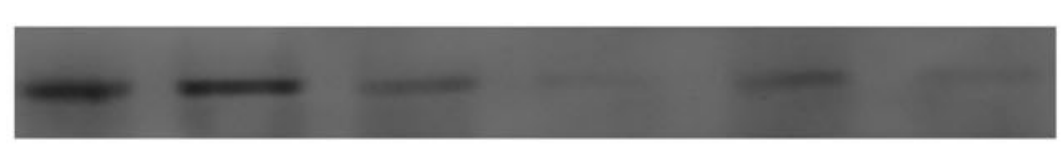

Gapdh

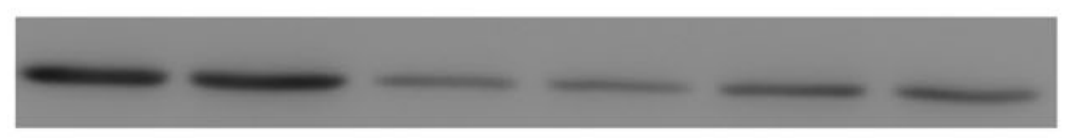

SV-HUC

T24

EJ

B

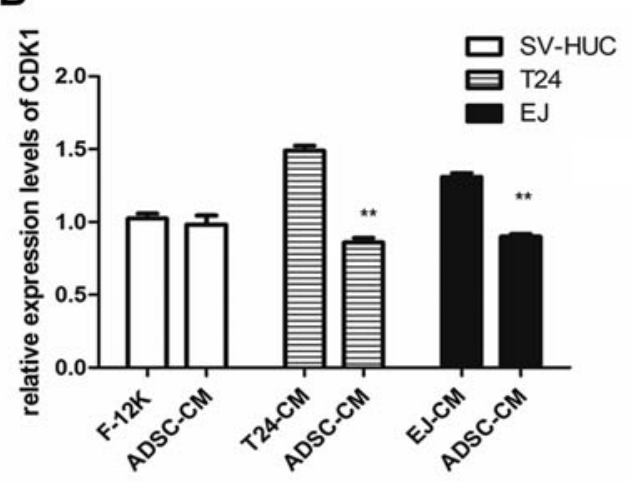

C
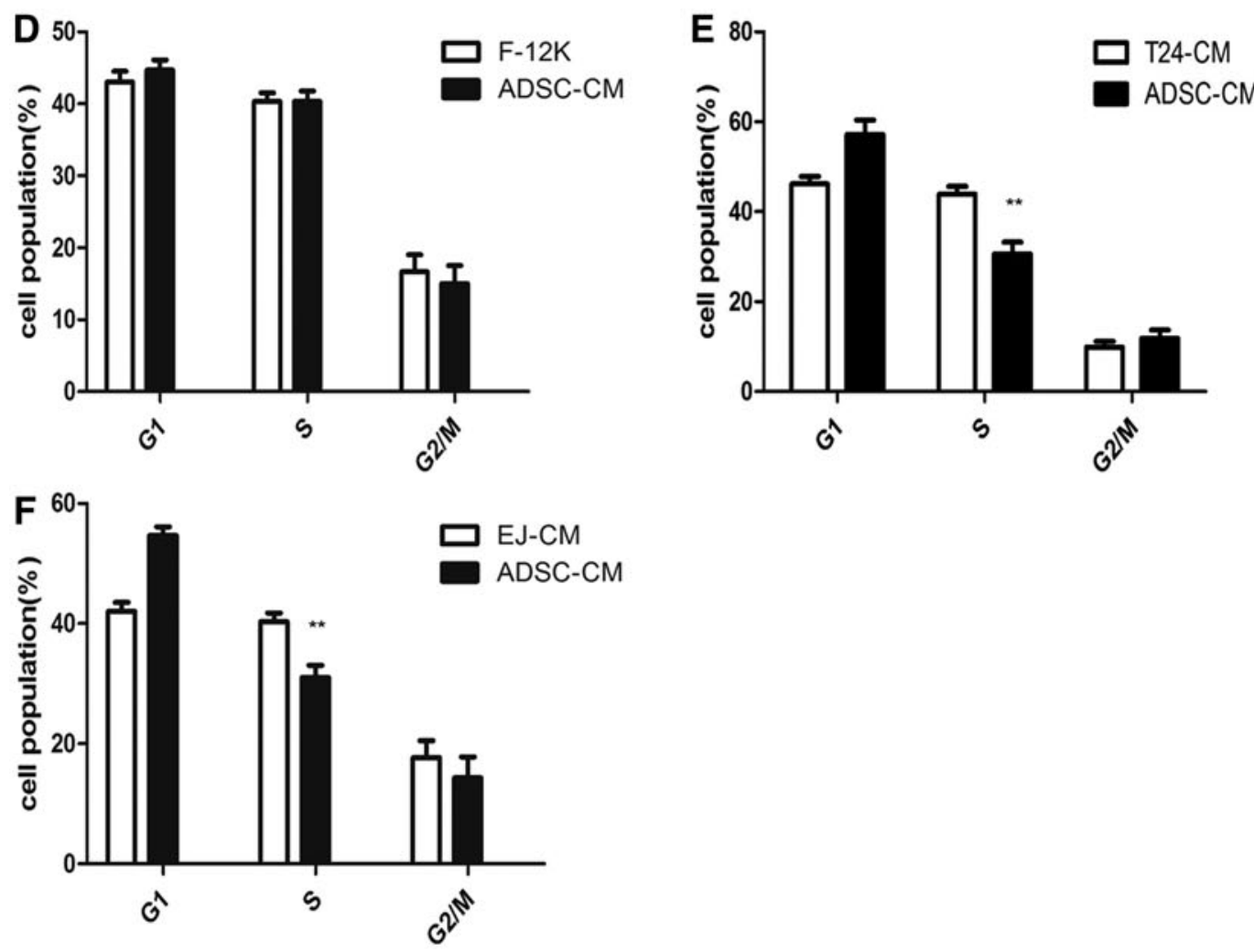

FIG. 2. The western blot showed that cyclin A level was increased and CDK1 level was decreased in ADSC-CM-treated T24 and EJ cells, but not in SV-HUC cells (A). Densitometry analysis of western blots showed quantitation of CDK1 (B) and cyclin A (C) levels. Cell cycle analysis of SV-HUC, T24, and EJ cells. There is no significance in SV-HUC groups (D). It shows an obvious S phase arrest with a concomitant decrease of cell number in G1 phase of the cell cycle in ADSCCM-treated T24 (E) and EJ (F) cells. ( ${ }^{* *} p<0.01$ vs. control). 

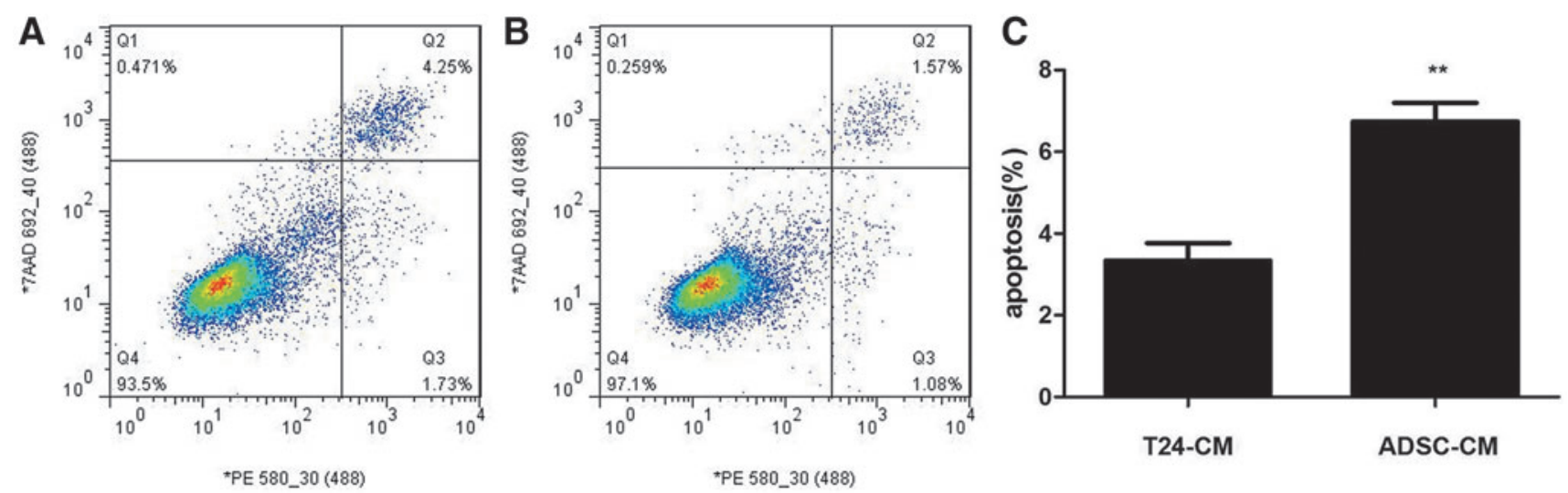

FIG. 3. ADSC-CM treatment induces apoptosis in T24 cells. Cells were analyzed by flow cytometry. The gate setting distinguished between living (bottom left), necrotic (top left), early apoptotic (bottom right), and late apoptotic (top right) cells. The apoptosis of T24 cells was increased in the ADSC-CM groups (A) than the T24-CM groups (B) from three independent experiments $(\mathbf{C})$. (**p<0.01 vs. control).

\section{Results}

\section{ADSCs inhibited the proliferation and viability of T24 and EJ cells}

ADSCs had a significant inhibitory effect on the proliferation of T24 and EJ cells. The number was not reduced when SV-HUC cells were cocultured with ADSCs (Fig. 1A), while a significant dose-dependent reduction in T24 (Fig. 1C) and EJ (Fig. 1E) cells number was observed at both 1:3 and 1:1 ratios with ADSCs. Next, we examined the viability of cells in the presence of ADSC-CM. As shown, ADSC-CM showed no significant inhibition in SV-HUC (Fig. 1B) cells, but inhibited the viability of T24 (Fig. 1D) and EJ (Fig. 1F) cells in a dosedependent manner compared to that observed in control cells.

\section{ADSC-CM interfered with T24 and EJ cells proliferation by inducing cell cycle arrest}

Western blotting was carried out to detect the impact of ADSC-CM on the expression of cyclin A and CDK1. The western blot showed that cyclin A level was increased and CDK1 level was decreased in ADSC-CM-treated T24 and EJ cells, but not in SV-HUC cells (Fig. 2A).

The expression of CDK1 (Fig. 2B) was decreased, whereas cyclin A (Fig. 2C) was increased in the ADSC-CM groups, suggesting that ADSC-CM evoked S phase arrest in T24 and EJ cells possibly through the dysregulation of CDK1 and cyclin A. Cell cycle analysis showed that there is no significance in SV-HUC groups (Fig. 2D), while $43.8 \%$ of the T 24 cells in the ADSC-CM groups were arrested at the $\mathrm{S}$ phase, $7.7 \%$ were arrested at the $\mathrm{G} 2 / \mathrm{M}$ phase, and $48.5 \%$ were arrested at the G1 phase of the cell cycle, whereas $30.8 \%$ of the cells in T24-CM groups were arrested at the $\mathrm{S}$ phase, $8.7 \%$ were arrested at the $\mathrm{G} 2 / \mathrm{M}$ phase, and $61.5 \%$ were arrested at the G1 phase of the cell cycle (Fig. 2E). The similar result was carried out in T24-CM-treated EJ cells (Fig. 2F).

\section{Induction of apoptosis in T24 cells by ADSC-CM}

Despite the inhibitory effects of ADSC-CM on proliferation and viability mentioned above as well as the ability of ADSC$\mathrm{CM}$ to induce $\mathrm{S}$ phase arrest, we speculated whether ADSC-CM also induced apoptosis in T24 cells. Apoptosis was observed more frequently in the ADSC-CM groups than in T24-CM groups. The ratio of apoptotic cells was significantly higher in the ADSC-CM groups (Fig. 3A) than in the T24-CM groups (Fig. 3B). Consistent with the results of MTS assay, these results revealed that ADSC-CM induced cellular apoptosis (Fig. 3C).

The mechanism of apoptosis in T24 cells induced by ADSC-CM. Caspase 3/7 was activated when cells underwent apoptosis.

In the ADSC-CM groups, caspase 3/7 expression was significantly increased compared with that in the T24-CM groups (Fig. 4).

\section{ADSC-CM activates $W n t / \beta$-catenin signaling in T24 cells}

To determine the association between ADSC-CM and the activation level of $\mathrm{Wnt} / \beta$-catenin signaling pathway, western blot analysis was used to assess the impacts of ADSC-CM on $\mathrm{Wnt} / \beta$-catenin signaling pathway in T2 4 cells. The expression of $\beta$-catenin was shown. While cultured in ADSC-CM, the expression of $\beta$-catenin was less than being cultured in T24CM (Fig. 5A, B). The result indicated that ADSC-CM could affect the activity of $\mathrm{Wnt} / \beta$-catenin pathway in T2 4 cells.

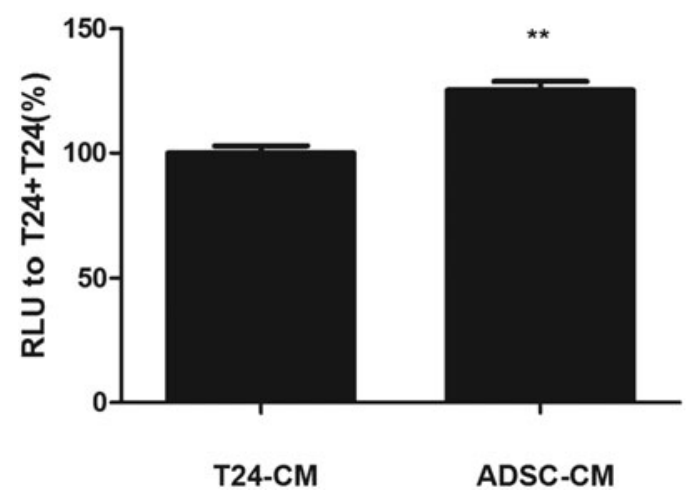

FIG. 4. Caspase 3/7 was measured in T24 cells treated with ADSC-CM or T24-CM. RLU of the cells with ADSC-CM to those with T24-CM was expressed as caspase 3/7 activity. $(* * p<0.01$ vs. control). RLU, relative luminescence. 
A

FIG. 5. The western blot showed $\beta$-catenin level was decreased in ADSC-CM groups (A). Densitometry analysis of western blots showed quantitation of $\beta$-catenin level (B). $(* * p<0.01$ vs. control).

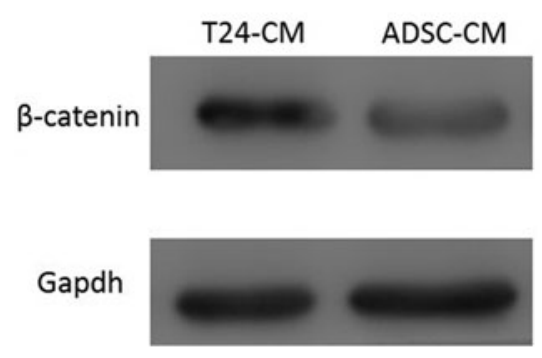

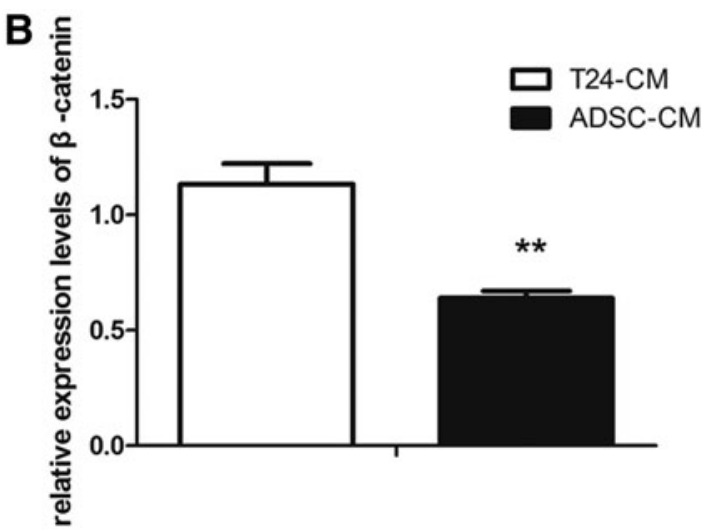

\section{Discussion}

In a series of experiments, we examined the antiproliferative and proapoptotic effects of ADSCs on T24 and EJ cells. Coculture experiments suggested that ADSCs directly inhibited T24 and EJ cell proliferation in a dosedependent manner. Then, we treated T24 and EJ cells with ADSC-CM to determine whether some secreted factors were involved in this inhibition. We found that ADSC-CM attenuated T24 and EJ cell viability in a dose-dependent manner.

These results suggested that ADSCs may secrete some soluble factors that influence T24 and EJ cell growth. Many studies have reported that the soluble factors of ADSCs (such as DKK-1, SDF-1, TGF- $\beta$. and RANTES), prostaglandins (such as PGE2, PGI2 and PGJ2) or interleukins (such as IL6, IL8, GSF, and IL11) have different effects on different tumors (Lamfers et al., 2009; Vilalta et al., 2009; Yu et al., 2015; Zhu et al., 2009).

Hariharan found that IL6 secreted by adipose tissue influenced the migration of BT cells and enhanced tumor progression (Hariharan et al., 2018). The researches on ADSC originated IL6 showed that it was a key promoter of BT progression (Chu et al., 2018; Lu et al., 2016). DKK-1, SDF-1, TGF- $\beta$, and RANTES have been found to increase the risk of developing bladder cancer in lots of researches (Fan et al., 2014; Kumari et al., 2017; Sun et al., 2015; Zhang et al., 2018).

However, this research based on the use of a conditioned medium suggested that the paracrine activity of ADSCs exert antitumor progression effects. We did not know which soluble factor was responsible for the observed effects. May be it referred to extracellular vesicles (EVs), such as apoptotic bodies and exosomes. Wu reported that EVs from human umbilical cord Wharton's jelly MSCs reversed the development of BT cells possibly by downregulating phosphorylation of Akt and upregulating cleaved caspase-3 (Wu et al., 2013).

Another research showed that ADSCs-derived exosomes inhibited prostate cancer via delivery of miR-145 by promoting apoptosis through the caspase-3/7 pathway and reducing the activity of Bcl-xL (Takahara et al., 2016). In the same way, EVs were found to inhibit proliferation and to promote apoptosis in Kaposi's sarcoma, liver carcinoma, and ovarian tumor cell lines (Bruno et al., 2013). Higher miRNA content as well as superior amounts of cytokines and adhesion molecules in exosomes might also be involved in the tumor-promoting effects. So, we intended to isolate exosome for further research.
According to the above results, ADSCs had an inhibitory impact on T24 and EJ cell proliferation. To discover the mechanism involved, we conducted cell cycle analysis using flow cytometry. Cell cycle analyses demonstrated that ADSC-CM exposure caused S-phase arrest in T24 and EJ cells and deregulation of cyclin $\mathrm{A}$ and $\mathrm{CDK} 1$, which are essential for the $\mathrm{S}$ to $\mathrm{G} 2 / \mathrm{M}$ transition. ADSC-CM-treated T24 and EJ cells did not progress into G2-M phase, were arrested in $\mathrm{S}$ phase, failed to accomplish normal mitosis, and ultimately perished by apoptosis.

Cyclin A accumulated at the G1/S phase transition and persisted through $\mathrm{S}$ phase. Cyclin A was initially associated with CDK2 in the late $S$ phase, and was then associated with CDK1. Cyclin A-associated kinase activity is required for entry into $\mathrm{S}$ phase, the completion of $\mathrm{S}$ phase, and entry into M phase (Wenzel and Singh, 2018). Cyclin A and CDK1 dysfunction provides an additional explanation for the $\mathrm{S}$ phase arrest induced by ADSC-CM. There was also some evidences that cyclin $\mathrm{A}$ and CDK1 began to form in late $\mathrm{S}$ phase and were overexpressed in G2 phase, resulting in the progression from $\mathrm{S}$ phase to $\mathrm{G} 2 / \mathrm{M}$ phase (Braun and Zischka, 2008; Yam et al., 2002; Zheng and Yu, 2018).

Apoptosis and cell cycle arrest are two different mechanisms involved in the induction of cell death (Choi et al., 2018; Jung et al., 2019; Masuda et al., 2018; Salha et al., 2018; Zhang et al., 2010). We found increased apoptosis in T24 cells in the ADSC-CM groups than those in the T24-CM groups and that caspase 3/7 expression was significantly increased. Among the caspase family, caspase 1 , caspase 11 , and possibly caspase 4 , are not directly involved in the transduction of apoptotic signals, they are mainly involved in the activation of interleukin precursors; caspase 2, caspase 8, caspase 9, and caspase 10 were involved. The initiation of apoptosis: caspase 3, caspase 6 , and caspase 7 are involved in the initiation of apoptosis, and caspase 3 and 7 have similar substrate polymerases that are involved in DNA repair and monitor gene integrity.

At the initiation of apoptosis, the $116 \mathrm{kDa}$ PARP protein is cut between Asp216-Gly217 into $31 \mathrm{kDa}$ and $85 \mathrm{kDa}$ fragments by caspase-3, making two zinc finger structures that bind to the DNA of PARP separated from the catalytic region at the carboxy terminus, which fails to function normally. As a result, the activity of $\mathrm{Ca}^{2+} / \mathrm{Mg}^{2+}$-dependent endonuclease, which is affected by the negative regulation of PARP, is increased, and DNA between nucleosomes is cleaved, causing apoptosis (Julien and Wells, 2017; Kim and Kim, 2018; Orning et al., 2018; Zeng et al., 2018; Zhu 
and $\mathrm{Li}, 2018$ ). Based on these results, we suggest that ADSC-CM induced T24 cell apoptosis via the caspase-3/7 pathway.

Aberrant activation of the $\mathrm{Wnt} / \beta$-catenin signaling pathway often occurred during the initiation and progression of BT (Chen et al., 2018b; Pei et al., 2017). As we know, $\mathrm{Wnt} / \beta$-catenin pathway was inactive due to inhibition of $\beta$-catenin expression and translocation to nucleus. Wnt/ $\beta$-catenin signaling is one of the important molecular mechanisms to regulate cell proliferation, invasion, and differentiation through $\beta$-catenin protein, which is an important signaling molecule in the $\mathrm{Wnt} / \beta$-catenin pathway (Sumithra et al., 2016; Tai et al., 2015). $\beta$-catenin accumulates in the cytoplasm and translocates to the nucleus, and then activates downstream target genes, such as c-myc and cyclin D1. In our study, we observed that ADSC-CM inhibited the nuclear translocation of $\beta$-catenin in T2 4 cell, which leads to suppression of $\mathrm{Wnt} / \beta$-catenin signaling pathway.

\section{Conclusion}

In summary, our results demonstrated that ADSCs could obviously inhibit the proliferation of T24 and EJ cells in a dose-dependent manner through apoptosis and S-phase arrest. The antiproliferative effect of ADSCs appeared to be associated with the secretion of soluble factors that were involved with caspase-3/7 and Wnt/ $\beta$-catenin signaling pathway. Further research was needed to clarify which soluble factor or EVs worked and whether it possessed the same effect on other BT in vivo.

\section{Acknowledgments}

The authors acknowledge the Institute of Urology, Peking University, for kindly providing SV-HUC, T24, and EJ cells. The authors in the list are also acknowledged.

\section{Author Disclosure Statement}

The authors declare that no conflicting financial interests exist.

\section{Funding Information}

This study was supported by Application and Basic Research Project of Wuhan City (No. 2018060401011321), Wuhan Morning Light Plan of Youth Science and Technology (No. 2017050304010281), Natural Science Foundation of Hubei Province (Nos. 2016CFB114, 2017CFB181).

\section{References}

Braun, R.J., and Zischka, H. (2008). Mechanisms of Cdc48/ VCP-mediated cell death: from yeast apoptosis to human disease. Biochim. Biophys. Acta 1783, 1418-1435.

Bruno, S., Collino, F., Deregibus, M.C., Grange, C., Tetta, C., and Camussi, G. (2013). Microvesicles derived from human bone marrow mesenchymal stem cells inhibit tumor growth. Stem Cells Dev. 22, 758-771.

Chen, B., Yu, J., Wang, Q., Zhao, Y., Sun, L., Xu, C., Zhao, X., Shen, B., Wang, M., Xu, W., and Zhu, W. (2018a). Human bone marrow mesenchymal stem cells promote gastric cancer growth via regulating c-Myc. Stem Cells Int. 2018, 9501747.
Chen, Z., Zhou, L., Wang, L., Kazobinka, G., Zhang, X., Han, X., Li, B., and Hou, T. (2018b). HBO1 promotes cell proliferation in bladder cancer via activation of Wnt/beta-catenin signaling. Mol. Carcinog. 57, 12-21.

Choi, S.A., Lee, C., Kwak, P.A., Park, C.K., Wang, K.C., Phi, J.H., Lee, J.Y., Chong, S., and Kim, S.K. (2018). Histone deacetylase inhibitor panobinostat potentiates the anti-cancer effects of mesenchymal stem cell-based sTRAIL gene therapy against malignant glioma. Cancer Lett. 442, 161-169.

Chu, Y., Tang, H., Guo, Y., Guo, J., Huang, B., Fang, F., Cai, J., and Wang, Z. (2015). Adipose-derived mesenchymal stem cells promote cell proliferation and invasion of epithelial ovarian cancer. Exp. Cell. Res. 337, 16-27.

Chu, Y., Wang, Y., Peng, W., Xu, L., Liu, M., Li J., Hu, X., Li, Y., Zuo, J., and Ye, Y. (2018). STAT3 activation by IL-6 from adipose-derived stem cells promotes endometrial carcinoma proliferation and metastasis. Biochem. Biophys. Res. Commun. 500, 626-631.

DeGeorge, K.C., Holt, H.R., and Hodges, S.C. (2017). Bladder cancer: diagnosis and treatment. Am. Fam. Physician. 96, 507-514.

Fan, Y., Shen, B., Tan, M., Mu, X., Qin, Y., Zhang, F., and Liu, Y. (2014). TGF-beta-induced upregulation of malat1 promotes bladder cancer metastasis by associating with suz12. Clin. Cancer. Res. 20, 1531-1541.

Gazdic, M., Simovic, M.B., Jovicic, N., Misirkic-Marjanovic, M., Djonov, V., Jakovljevic, V., Arsenijevic, N., Lukic, M.L., and Volarevic, V. (2017). Mesenchymal stem cells promote metastasis of lung cancer cells by downregulating systemic antitumor immune response. Stem Cells Int. 2017, 6294717.

Hariharan, N., Ashcraft, K.A., Svatek, R.S., Livi, C.B., Wilson, D., Kaushik, D., Leach, R.J., and Johnson-Pais, T.L. (2018). Adipose tissue-secreted factors alter bladder cancer cell migration. J. Obes. 2018, 9247864.

Jin, X., Yun, S.J., Jeong, P., Kim, I.Y., Kim, W.J., and Park, S. (2014). Diagnosis of bladder cancer and prediction of survival by urinary metabolomics. Oncotarget 5, 1635-1645.

Jing, H.X., Duan, D.J., Zhou, H., Hu, Q.M., and Lei, T.C. (2016). Adiposederived mesenchymal stem cellfacilitated TRAIL expression in melanoma treatment in vitro. Mol. Med. Rep. 14, 195-201.

Julien, O., and Wells, J.A. (2017). Caspases and their substrates. Cell Death Differ. 24, 1380-1389.

Jung, P.Y., Ryu, H., Rhee, K.J., Hwang, S., Lee, C.G., Gwon, S.Y., Kim, J., Kim, J., Yoo, B.S., Baik, S.K., Bae, K.S., and Eom, Y.W. (2019). Adipose tissue-derived mesenchymal stem cells cultured at high density express IFN-beta and TRAIL and suppress the growth of H460 human lung cancer cells. Cancer Lett. 440-441, 202-210.

Kim, H.M., and Kim, Y.M. (2018). HMGB1: LPS delivery vehicle for caspase-11-mediated pyroptosis. Immunity 49, 582-584.

Kumari, N., Agrawal, U., Mishra, A.K., Kumar, A., Vasudeva, P., Mohanty, N.K., and Saxena, S. (2017). Predictive role of serum and urinary cytokines in invasion and recurrence of bladder cancer. Tumour Biol. 39, 1010428317697552.

Lamfers, M., Idema, S., van Milligen, F., Schouten, T., van der Valk, P., Vandertop, P., Dirven, C., and Noske, D. (2009). Homing properties of adipose-derived stem cells to intracerebral glioma and the effects of adenovirus infection. Cancer Lett. 274, 78-87.

Lu, J.H., Wei, H.J., Peng, B.Y., Chou, H.H., Chen, W.H., Liu, H.Y., and Deng, W.P. (2016). Adipose-derived stem cells enhance cancer stem cell property and tumor formation ca- 
pacity in Lewis lung carcinoma cells through an interleukin-6 paracrine circuit. Stem Cells Dev. 25, 1833-1842.

Masuda, J., Takayama, E., Ichinohe, T., Strober, W., MizunoKamiya, M., Ikawa, T., Kitani, A., Kawaki, H., Fuss, I., Kawamoto, H., Seno, A., Vaidyanath, A., Umemura, N., Mizutani, A., Kasai, T., Honjo, Y., Satoh, A., Murakami, H., Katsura, Y., Kondoh, N., and Seno, M. (2018). Suppression effect on IFN-gamma of adipose tissue-derived mesenchymal stem cells isolated from beta2-microglobulin-deficient mice. Exp. Ther. Med. 16, 4277-4282.

Nielsen, E.O., Chen, L., Hansen, J.O., Degn, M., Overgaard, S., and Ding, M. (2018). Optimizing osteogenic differentiation of ovine adipose-derived stem cells by osteogenic induction medium and FGFb, BMP2, or NELL1 in vitro. Stem Cells Int. 2018, 9781393.

Orning, P., Weng, D., Starheim, K., Ratner, D., Best, Z., Lee, B., Brooks, A., Xia, S., Wu, H., Kelliher, M.A., Berger, S.B., Gough, P.J., Bertin, J., Proulx, M.M., Goguen, J.D., Kayagaki, N., Fitzgerald, K.A., and Lien, E. (2018). Pathogen blockade of TAK1 triggers caspase-8-dependent cleavage of gasdermin D and cell death. Science 362, 1064 1069.

Pei, Z., Du X, Song, Y., Fan, L., Li, F., Gao, Y., Wu, R., Chen, Y., Li, W., Zhou, H., Yang, Y., and Zeng, J. (2017). Downregulation of lncRNA CASC2 promotes cell proliferation and metastasis of bladder cancer by activation of the Wnt/betacatenin signaling pathway. Oncotarget 8, 18145-18153.

Salha, S., Gehmert, S., Brebant, V., Anker, A., Loibl, M., Prantl, L., and Gehmert, S. (2018). PDGF regulated migration of mesenchymal stem cells towards malignancy acts via the PI3K signaling pathway. Clin. Hemorheol. Microcirc. 70, 543-551.

Siegel, R.L., Miller, K.D., and Jemal, A. (2019). Cancer statistics, 2019. CA Cancer J. Clin. 69, 7-34.

Sumithra, B., Saxena, U., and Das, A.B. (2016). Alternative splicing within the Wnt signaling pathway: role in cancer development. Cell Oncol (Dordr). 39, 1-13.

Sun, D.K., Wang, L., Wang, J.M., and Zhang, P. (2015). Serum Dickkopf-1 levels as a clinical and prognostic factor in patients with bladder cancer. Genet. Mol. Res. 14, 18181-18187.

Tai, D., Wells, K., Arcaroli, J., Vanderbilt, C., Aisner, D.L., Messersmith, W.A., and Lieu, C.H. (2015). Targeting the WNT signaling pathway in cancer therapeutics. Oncologist 20, 1189-1198.

Takahara, K., Ii, M., Inamoto, T., Nakagawa, T., Ibuki, N., Yoshikawa, Y., Tsujino, T., Uchimoto, T., Saito, K., Takai, T., Tanda, N., Minami, K., Uehara, H., Komura, K., Hirano, H., Nomi, H., Kiyama, S., Asahi, M., and Azuma, H. (2016). microRNA-145 mediates the inhibitory effect of adipose tissue-derived stromal cells on prostate cancer. Stem Cells Dev. 25, 1290-1298.

Vilalta, M., Degano, I.R., Bago, J., Aguilar, E., Gambhir, S.S., Rubio, N., and Blanco, J. (2009). Human adipose tissuederived mesenchymal stromal cells as vehicles for tumor bystander effect: a model based on bioluminescence imaging. Gene Ther. 16, 547-557.
Wenzel, E.S., and Singh, A. (2018). Cell-cycle checkpoints and aneuploidy on the path to cancer. In Vivo 32, 1-5.

Wu, S., Ju, G.Q., Du T, Zhu, Y.J., and Liu, G.H. (2013). Microvesicles derived from human umbilical cord Wharton's jelly mesenchymal stem cells attenuate bladder tumor cell growth in vitro and in vivo. PLoS One 8, e61366.

Yam, C.H., Fung, T.K., and Poon, R.Y. (2002). Cyclin A in cell cycle control and cancer. Cell. Mol. Life Sci. 59, 1317-1326.

Yu, X., Su, B., Ge, P., Wang, Z., Li, S., Huang, B., Gong, Y., and Lin, J. (2015). Human adipose derived stem cells induced cell apoptosis and s phase arrest in bladder tumor. Stem Cells Int. 2015, 619290.

Zachar, V., Rasmussen, J.G., and Fink, T. (2011). Isolation and growth of adipose tissue-derived stem cells. Methods Mol. Biol. 698, 37-49.

Zeng, L., Qian, J., Luo, X., Zhou, A., Zhang, Z., and Fang, Q. (2018). CHSY1 promoted proliferation and suppressed apoptosis in colorectal cancer through regulation of the NFkappaB and/or caspase-3/7 signaling pathway. Oncol. Lett. 16, 61406146.

Zhang, T., Yang, F., Li, W., Liu, B., Li, W., Chen, Z., and Wang, C. (2018). Suppression of the SDF1/CXCR4/betacatenin axis contributes to bladder cancer cell growth inhibition in vitro and in vivo. Oncol. Rep. 40, 1666-1674.

Zhang, Y., Bellows, C.F., and Kolonin, M.G. (2010). Adipose tissue-derived progenitor cells and cancer. World J. Stem Cells 2, 103-113.

Zheng, G., and Yu, H. (2018). Cyclin A turns on Bora to light the path to mitosis. Dev. Cell 45, 542-543.

Zhu, X., and Li, S. (2018). TET2 inhibits tumorigenesis of breast cancer cells by regulating caspase-4. Sci. Rep. 8, 16167.

Zhu, Y., Sun, Z., Han, Q., Liao, L., Wang, J., Bian, C., Li, J., Yan, X., Liu, Y., Shao, C., and Zhao, R.C. (2009). Human mesenchymal stem cells inhibit cancer cell proliferation by secreting DKK-1. Leukemia 23, 925-933.

Address correspondence to: Xiuheng Liu

Department of Urology

Renmin Hospital of Wuhan University No. 99 Zhang Zhidong Road Wuhan 430060

China

E-mail:drliuxh@hotmail.com

Shenglan $\mathrm{Li}$

Department of Radiography Renmin Hospital of Wuhan University No. 99 Zhang Zhidong Road Wuhan 430060

China

E-mail:454169993@qq.com 